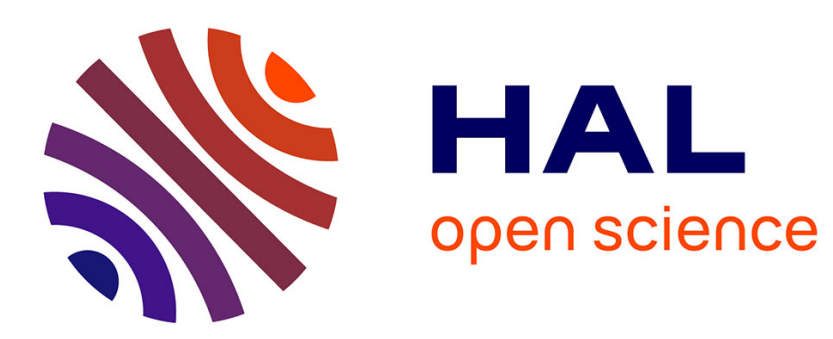

\title{
Health status recovery at one year in children injured in a road accident: A cohort study
}

\author{
Pierre Batailler, Martine Hours, Maud Maza, Pierrette Charnay, Hélène
}

Tardy, Charlène Tournier, Etienne Javouhey

\section{- To cite this version:}

Pierre Batailler, Martine Hours, Maud Maza, Pierrette Charnay, Hélène Tardy, et al.. Health status recovery at one year in children injured in a road accident: A cohort study. Accident Analysis \& Prevention, 2014, 71, pp. 267-272. 10.1016/j.aap.2014.06.001 . hal-01068249

\section{HAL Id: hal-01068249 \\ https://hal.science/hal-01068249}

Submitted on 25 Sep 2014

HAL is a multi-disciplinary open access archive for the deposit and dissemination of scientific research documents, whether they are published or not. The documents may come from teaching and research institutions in France or abroad, or from public or private research centers.
L'archive ouverte pluridisciplinaire HAL, est destinée au dépôt et à la diffusion de documents scientifiques de niveau recherche, publiés ou non, émanant des établissements d'enseignement et de recherche français ou étrangers, des laboratoires publics ou privés. 


\section{Title page:}

Health status recovery at one year in children injured in a road accident: a cohort study

Pierre Batailler, MSc ${ }^{\mathrm{a}}$, Martine Hours, MD, PhD ${ }^{\mathrm{a}}$, Maud Maza, MSc ${ }^{\mathrm{a}}$, Pierrette Charnay, MSc ${ }^{\mathrm{a}}$, Hélène Tardy, MSc ${ }^{\mathrm{a}}$, Charlène Tournier, MSc ${ }^{\mathrm{a}}$, Etienne Javouhey, MD, $\mathrm{PhD}^{\mathrm{a}, \mathrm{b}}$

a. Epidemiological Research and Surveillance Unit in Transport Occupation and Environment Université de Lyon, F-69622, Lyon, France ; Université Lyon 1, UMRESTTE, F-69373 Lyon ; IFSTTAR, UMRESTTE, F-69675 Bron.

b. Pediatric intensive care unit, Hôpital Femme Mère Enfant, Hospices Civils of Lyon, Bron, France

Corresponding Author:

Pr Etienne Javouhey, MD, PhD

Affiliations: Pediatric Intensive Care Unit, Hospices Civils of Lyon, Lyon-Bron, France and IFSTTAR, UMRESTTE, Bron.

Pediatric Intensive Care Unit, Hôpital Femme Mère Enfant, 59 Boulevard Pinel, 69677 Bron Cedex, France

Phone: 33472129735

Fax: 33427869270

Email: etienne.javouhey@chu-lyon.fr 


\section{Abstract:}

Despite frequency of traumatic injuries due to road accident and potential importance of identifying children at risk of altered recovery one year after a road accident, there is a lack of study on long term recovery of health status, except in children with severe traumatic brain injury. The aim of the present study was to evaluate predictive factors of recovery in children one year after road traffic injuries. This prospective cohort study was composed of children aged $<16$ years, hospitalized in public or private health hospitals of the Rhône administrative area following a road accident. The recovery of health status one year after the accident and information concerning quality of life and consequences of the accident for the child or his family 1 year after the accident were collected thanks to questionnaires completed most of the time by parents. Victims were in majority Male (64.6\%) and had mild or moderate injuries $(81.9 \%$ with Maximum Abbreviated Injury Scale (M-AIS) $<3)$. One year after the accident, $75.0 \%$ of the mild to moderate and $34.8 \%$ of the severe cases estimated their health status as fully recovered. After adjustment, severity score (M-AIS $\geq 3$ ) and lower limb injury (AIS $>1)$ were associated with incomplete recovery of health status: Weighted Odds Ratio $\left(\mathrm{OR}_{\mathrm{w}}\right), 4.3$ [95\% Confidence Interval (95\% CI), 1.3-14.6] and $\mathrm{OR}_{\mathrm{w}}, 6.5$ [95\% CI, 1.9-21.7] respectively. The recovery status was significantly correlated to quality of life Physical scores $(r=0.46)$ especially to Body Pain $(r=0.48)$ and Role/Social - physical $(r=0.50)$ and, to a lesser extent, to quality of life Psychosocial scores $(\mathrm{r}=0.21)$. In a cohort of children injured in a road accident, those with high injury severity score and those with lower limb injuries are less likely to fully recover their health status at 1 year. Altered health status was associated with a lower physical quality of life score at 1 year.

Keywords: cohort study; one year follow-up; child; road traffic accident; injury; recovery of function 


\section{INTRODUCTION:}

According to the Rhône area registry of road traffic casualties, the mean annual incidence of road traffic injury in children was 420 per 100000 children between 2003 and 2009 (Javouhey et al. 2012). It's still one of the leading causes of injury and death of children and adolescents in high income countries (Peden et al. 2008, Chandran et al. 2010). In adults, long-term impact of these injuries on the quality of life, physical and psychological health status is widely described in literature (Barnes and Thomas 2006, Soberg et al. 2007, Nhac-Vu et al. 2011) but little is known concerning outcome after road traffic injuries in children. Haukeland highlighted that adults have far more severe health problems associated with a more diminished well-being than children after traffic injuries (Haukeland 1996). Studying consequences of trauma in children, Wesson et al. found that $54 \%$ of children with minor injuries (ISS $<16$ ) and $71 \%$ of children with major injuries (ISS $\geq 16$ ) had persistent physical limitations at 12 months (Wesson et al. 1992). Aitken et al. showed differences of physical health summary scores in the Children Health Questionnaires (CHQ) between the injured children and the norm which persisted 6 months after traumatism(Aitken et al. 2002). Nevertheless, the majority of studies targeted children with traumatic brain injuries (TBI) and evaluated their consequences on the child and his family (Max et al. 1998, Waters et al. 2001, Anderson et al. 2005b, Aitken et al. 2009). Other types of injuries due to road traffic accidents could also affect children's health related quality of life (HRQoL), especially lower limb injuries which were compared to TBI in some studies and may also have an impact on the physical condition of children (Stancin et al. 2002). Factors of recovery after a road traffic accident and specifically outcomes of children injured in road accidents, whatever the type and the severity of injuries, are less described and have rarely been assessed.

A cohort study named ESPARR (Hours et al. 2010, Nhac-Vu et al. 2011) (Etude et Suivi d'une Population d'Accidentés de la Route dans le Rhône: Rhône area road traffic accident victim follow-up study) has been conducted in the Rhône administrative area (1.6 million of inhabitants, France) in order to determine the long term outcomes of patients injured in a road accident. Victims of road traffic accidents were followed during 5 years with regular assessments of their health status, of their physical and social conditions and their impact on family and environment. 
The aim of the present study was to assess predictive factors of recovery one year after road traffic injuries in children of the ESPARR cohort. 


\section{METHODS:}

\subsection{The ESPARR cohort}

The ESPARR cohort is linked to the Rhône area registry of road traffic casualties (Charnay and Laumon 2002), which records all road traffic accident casualties seeking medical care in public or private health facilities of the Rhône administrative area. Inclusion criteria were: to be injured in a road traffic accident, involving at least one mechanical means of transport, and occurring in the Rhône administrative area; having been admitted to one of the area's hospital emergency departments; having survived the crash until hospital admission; being resident in the same area (to facilitate follow-up) (Hours et al. 2010).

From October 2004 to July 2006, the Rhône Road Trauma Registry recorded 10765 victims of road accidents, of whom 1410 were younger than 16 years. Among the 1322 patients included in the ESPARR cohort, 204 (14.9\%) were younger than 16 years and were included in the pediatric ESPARR cohort. The recruitment differed depending on the maximum injury severity of the Abbreviated Injury Scale (AIS 90; AAAM, 1990). The objective was to include all children with M-AIS $\geq 3$ and one out of six children with M-AIS $<3$. In fact $25.6 \%$ of children of the registry with M-AIS $\geq 3$ and $13.4 \%$ of children of the registry with M-AIS $<3$ were included. The presence of interviewers in emergency wards was planned accordingly. For casualties with M-AIS $<3$, a cluster sampling framework was set up in the emergency wards: days were divided into 3 shifts of 5 hours $(8 \mathrm{am}-1 \mathrm{pm} ; 1 \mathrm{pm}-6 \mathrm{pm} ; 6 \mathrm{pm}-11 \mathrm{pm})$. In the two main teaching hospitals in the study area, an interviewer was present in the emergency wards during 1 in 3 shifts; in other general hospitals, 1 or 2 shifts per week were sampled at random. Interviewers asked all crash victims admitted during the shift and meeting the inclusion criteria to participate in the study. Casualties with M-AIS $\geq 3$ were identified during the interviewer's daily visits to other wards in the two major hospitals. Parents or caregivers were interviewed as soon as possible after the crash and signed informed consent to the follow-up of their child.

The study protocol was submitted and approved by the local ethics committee, called "CCPPRB", and by the French Ministry of Research. Collection and data analysis were approved by "CNIL", the national data protection authority. 


\subsection{Initial collected data}

Demographic variables as age at the accident and gender were included in the analysis as well as variable concerning living in an Urban renewal area. The age was divided into 3 categories: less than 6 years, 6 to 11 years and 12 to 15 years in order to have sufficient size categories respecting the different type of road user. A Familial socio-professional level variable was created by combining five others variables: mono or bi-parental status, the working status of each parent and the occupational category of each parent. For the number of persons in the household, we used a dichotomized variable: living with one to four persons and living with at least five persons. Type of road user variable was divided into four categories according to their mode of transport: four-wheeled occupants, motorized two-wheeled drivers, pedestrian and other (cyclists, Scooter/rollerblade users).The injury severity was measured by the AIS, which standardizes injury data and scores lesions from 1 (minor) to 6 (fatal); MAIS, the score of the most severe injury. Injuries of AIS 2 or more were also classified by body part involved: (head, face, neck, spine, chest, abdomen, upper limbs, lower limbs and external lesions).

\subsection{Outcome measures at follow-up:}

Six months and one year after the accident, standardized questionnaires were sent to parents or caregivers of each participant in order to assess the child's health, social, emotional and familial status as well as professional and financial status of the family. These questionnaires were either sent by mail, followed by reminder telephone calls, or completed during a face-to-face interview.

Concerning health status recovery, a standard question was used: "According to you, what is the health status of your child today?", with five response options ("Fully recovered", "Improved but not recovered", "Stabilized", "Deteriorated" or "Unknown”), dichotomized for analysis as "Fully recovered" versus "Not fully recovered", the latter combining all four remaining response options. There were three versions of the one year questionnaire. The "light" version of the questionnaire doesn't include the recovery status (15 children). The variable was completed thanks to the answer of the 6 months questionnaire when it was possible: it concerned three children. Six of the eight missing values of recovery status in the "short" and "long" questionnaires were completed with the 6 months questionnaire as well. 
Consequences of the accident for the child or his family one year after the crash were evaluated thanks to seven dichotomous variables: "Modification of one parent's occupation", "financial difficulties following the accident", "changes in leisure activities", "mood affected more than 6 months", "impact on school level", "body pain" and " presence of physical impairment". Missing values were excluded of these analyses.

Quality of life was evaluated with the Child Health Questionnaire-Parents Form 50 (CHQPF50) questionnaire composed of 12 scales: physical functioning, role/social-emotional/behavioral (which assessed emotional/behavioral consequences of the accident on social activities), role/socialphysical (which assessed physical consequences of the accident on social activities), bodily pain, general behavior, mental health, self-esteem, general health perceptions, parental impact-emotional, parental impact-time, family activities and family cohesion. These domains are summarized with 2 global scores: physical score and psychosocial score (Landgraf et al. 1998, HealthActCHQ 2008).

\subsection{Statistical analysis:}

In order to assess representativeness, the study population was compared to a reference group which was children $<16$ years included in the Rhône Registry between 10/01/2004 and 12/31/2005 and not included in ESPARR cohort. Nominal variables were compared using $\chi^{2}$ test or Fisher's exact test when necessary, and quantitative variables were compared using student's $t$-test. Predictive factors of incomplete recovery one year after the crash were sought among the following data: sociodemographic data (gender, age, family condition, socio-professional level and living in an urban renewal area), accident and medical data (type of vehicle, M-AIS, type of injury). Due to differing inclusion rules depending on severity of injuries, we used weighted logistic regressions for univariate and multivariate analyses. Variables were included in multivariate model if Wald's test of weighted univariate logistic regressions were significant at a $20 \%$ threshold. Gender and age, considered as adjustment variables, were included in the multivariate analysis regardless of their significance level. Familial socio-professional level was controlled in multivariate models. Stepwise selection with backward elimination of subjective health status predictors was applied, with $\mathrm{p}>0.05$ for exclusion. Weighted univariate analyses were used to compare consequences one year after the accident according to the recovery. Correlations between the health status recovery and each domain of the 
CHQ-PF50 quality of life questionnaire were assessed using non parametric Spearman method.

Statistical Analysis System software, version 9.3 for Windows (SAS Institute, Cary, NC, USA) was used for all analyses. 


\section{RESULTS:}

\subsection{Description of the study population}

The pediatric ESPARR cohort was composed of 204 children $<16$ years. Sixty three hadn't responded to one year's questionnaire and were excluded. Twelve had responded to the "light" questionnaire and two to the "0-3 year" questionnaire which didn't contain the recovery status variable. It wasn't possible to complete the recovery status of these fourteen children with the 6 months questionnaire so they were excluded too. Analyses were finally focused on 127 children.

The cohort was compared to the registry data (excluding the ESPARR cohort) depending on M-AIS and only significantly differed from the pediatric registry population regarding the type of road user. Children having an M-AIS $<3$ injury included in the ESPARR cohort were more frequently injured as car passengers and less frequently as cyclists and inline-skate/ scooter users ( $\mathrm{p}=.01)$. For children with M-AIS $\geq 3$ injury, there were more motorcycle users and pedestrians and less inlineskate/scooter users $(\mathrm{p}=.04)$ (Table 1$)$.

The cohort was composed of around two thirds (64.6\%) males. The majority of children had M-AIS $<3$ injuries (81.9\%). There were almost as many children from 6 to 11 years $(40.9 \%)$ and from 12 to 15 years $(40.2 \%)$ and two times less children $<6$ years $(18.9 \%)$. Eighty six children $(67.7 \%)$ had fully recovered their health status and among the 41 children (32.3\%) who hadn't fully recovered, 31 (24.4\%) had improved but not fully recovered, 4 (3.2\%) were stabilized, 4 (3.2\%) had deteriorated and $2(1.6 \%)$ were unknown. Children who hadn’t fully recovered at one year were more likely severely injured $(p<.001)$, had more frequently lower limb injuries $(p<.001)$ and head injuries $(p=.05)$ than those who had fully recovered. Younger children ( $<6$ years) had more frequently a 1 year fully recovered health status than children of 12-16 years $(\mathrm{p}=.04)$ (Table 2$)$.

Compared to children having completely recovered, children with a not fully recovered health status had more frequent difficulties in school $(50.0 \%$ versus $15.5 \%$ corresponding to a Weighted Odds Ratio $\left(\mathrm{OR}_{\mathrm{w}}\right), 5.3$ [95\% Confidence Interval $\left.\left.(95 \% \mathrm{CI}), 1.8-15.7\right]\right)$. An incomplete recovery was also more frequently associated with modification of leisure activities $\left(52.5 \%\right.$ versus $11.0 \%$ : $\mathrm{OR}_{\mathrm{w}}, 7.5$ [95\% CI, 2.9-19.5]) and to a mood affected during more than 6 months $\left(38.5 \%\right.$ versus $17.4 \%$ : $\mathrm{OR}_{\mathrm{w}}$, 2.8 [95\% CI, 1.1-7.1]). Furthermore a not full recovery of health status was more frequently associated 
to financial difficulties (30.6\% versus $5.9 \%$ : $\left.\mathrm{OR}_{\mathrm{w}}, 5.6[95 \% \mathrm{CI}, 1.7-18.1]\right)$ and to a modification of one parent's occupation (46.2\% versus $9.0 \%$ : $\mathrm{OR}_{\mathrm{w}}, 8.2$ [95\% CI, 2.9-22.8]). The health status recovery was also associated with body pain and physical impairment one year after the accident: $77.5 \%$ of children who had not fully recovered health status had body pain versus $10.8 \%$ when the recovery was complete $\left(\mathrm{OR}_{\mathrm{w}}, 33.0\right.$ [95\% CI, 11.0-98.7]). Physical impairment one year after the accident concerned $66.7 \%$ of children with not fully recovered health status compared to $20.8 \%$ children with a fully recovered health status $\left(\mathrm{OR}_{\mathrm{w}}, 6.4[95 \% \mathrm{CI}, 2.6-15.9]\right)$.

\subsection{Predictive factors of medical condition 1 year after the accident}

Multivariate analyses found two main factors linked to the health status recovery. Indeed after adjustment for the baseline characteristics, the severity of injuries (MAIS $\geq 3$ ) and lower limb injuries with AIS $>1$ were both significantly associated with incomplete health status recovery (adjusted $\mathrm{OR}_{\mathrm{w}}$, 4.3 [95\% CI, 1.3-14.6] and adjusted $\mathrm{OR}_{\mathrm{w}}, 6.5$ [95\% CI, 1.9- 21.7] respectively) (Table 3). We didn't find any significant association with gender, age, type of vehicle, family situation, familial socioprofessional level and the other injuries.

\subsection{Correlation between health status recovery and quality of life}

Parent-report full health status recovery was significantly correlated with the two overall scores of CHQ-PF50. However correlation coefficients were higher with physical scores ( $\mathrm{r}=0.46$ $[\mathrm{p}<.001]):$ role/social - physical $(\mathrm{r}=0.50[\mathrm{p}<.001])$, body pain $(\mathrm{r}=0.48[\mathrm{p}<.001])$ then with psychosocial scores $(\mathrm{r}=0.21[\mathrm{p}=.049])$ : role/ social limitation-emotional $(\mathrm{r}=0.31[\mathrm{p}=.003])$, parent impact-emotional $(\mathrm{r}=0.34[\mathrm{p}=.001])$. Family activities and cohesion scores were not significantly dependent of health status recovery. It was also the case of mental health, behavior and self-esteem scores (Table 4) 


\section{DISCUSSION:}

The main finding of the study is that $32.3 \%$ of children injured in a road accident had not fully recovered their health status at one year according to their caregivers. Even in children with mild or moderate injury (M-AIS $<3$ ), 25\% had not fully recovered their health status after 1 year. These longterm consequences of mild or moderate injuries after a traffic accident are less well known and probably underestimated. Parents, caregivers and physicians should be aware of these outcomes. A specific follow-up could be useful in the most severely injured children in order to help them and their family to cope with persistent impairments and disabilities. Lower limb injuries seem to have important consequences on children's health status 1 year after the accident. Indeed the recovery of health status was lower when children had lower limb injuries compared to other injuries, which is consistent with Ding et al. findings(Ding et al. 2006). McCarthy et al. found that $40 \%$ of children with AIS $>1$ TBI had an altered QoL at one year and those who had concomitant lower extremity fractures were at risk of impaired physical function, according to the Pediatric QoL Inventory (PedsQL) (McCarthy et al. 2006). The same results were found among adult trauma patients (MacKenzie et al. 1988) as well as in adult ESPARR cohort (Nhac-Vu et al. 2011). It seems that younger children (0-5 years) had a better recovery than older children one year after injuries but this difference wasn't significant in multivariate analysis probably because of the limited number of children included in the study. This finding has been previously reported(Gofin et al. 1999). Nevertheless, this difference may also be due, at least in part, to difficulties of parents of young children to evaluate their recovery level. It is the case of body pain in infants and young children which can be underestimated by caregivers.

We didn't find any associations between TBI and recovery status in multivariate analysis, while, in univariate analysis, the recovery was significantly lower for TBI than for other injuries $(p=0.045)$. This finding may have several explanations. First, the number of TBI was small $(n=31)$ which explains the wide confidence intervals. Second, the evaluation of TBI recovery may not be as reliable as for other injuries. Children with TBI are more prone to develop psychological or behavioural disorders and are more likely to have persistent cognitive impairments like executive function disability or memory disorder (Taylor et al. 1999, Anderson et al. 2005a). In our study, health 
status recovery was mainly correlated with physical QoL domains, body pain and physical impairments. Social activities of children were essentially impacted by physical impairments one year after the accident. The emotional consequences of the accident seemed to have a more limited impact on children social activities. Cognitive and behaviour impairments are less easily assessable by parents. Consequently, it is likely that health status recovery reported by parents or caregivers underestimated these disabilities.

\subsection{Strengths and Limitations}

Long term consequences of Traumatic Brain Injuries (TBI) have frequently been studied especially for moderate and severe injuries (Stancin et al. 2002). McCarthy et al. showed that there is a strong relationship between the severity of TBI and QoL during the first year after injury (McCarthy et al. 2006). Aitken et al. found that family burden was greater when the health care need was unmet (Aitken et al. 2009). However, little is known concerning the impact of other injuries. The ESPARR cohort has for objective to determine the long term outcomes of patients one year after a road traffic accident. The other strength of this study is that this prospective cohort was composed of a homogeneous population of children involved in road traffic accidents, representative sample of the Rhône Road Trauma Registry.

There were some limitations to consider in this study. First, questionnaires were completed by parents (or caregivers) most of time (79.5\%), especially when for children under 12 years. Parentsreported health status reliability is an important debate in literature of children QoL (Eiser and Morse 2001). Some studies found that parents overestimate their child health status (Sturms et al. 2003, Polinder et al. 2005) and it would be interesting to have the child's point of view in future studies. Second, the comparison of the cohort characteristics with those of the registry highlighted a lower rate of cyclist and rollerblade/scooter users in the cohort. An explanation could be that injured children were reported to investigators by the medical staff who didn't always consider this kind of accident as road traffic accidents. It leads to an overrepresentation of accidents with motorized vehicles. Third, it's necessary to consider the sample attrition (37.7\%) due to non-respondent to 1 year questionnaire 
$(\mathrm{n}=63)$ and missing values $(\mathrm{n}=14)$. Dropouts only differed from participants in term of familial socioprofessional level which was taken into account in analysis. Indeed non-respondents to 1 year questionnaire had more frequently a low familial socio-professional level than respondents. Stancin et al. observed the same difference of socioeconomic conditions between participants and dropouts (Stancin et al. 2002). The study population being rather small, although it's necessary to considered that not significant results don't mean absence of association. Further studies with a larger population are needed to confirm these results. Finally, Clinical tests were performed only for TBI and severely injured patients. These data weren't analysed in order to preserve the same data collection method for all the study population. Moreover, the objective was to focus on the recovery on the perspective of the child and his family and not according to clinical data.

\section{Conclusion}

To conclude, 1 year after a road traffic accident, roughly one third of children kept altered health status even in mild injured children. Caregivers and physicians should be aware of possible impairments even after mild injuries and should organize a more systematic follow-up of the most severely injured children and those with lower limb injury. As this study did not assess cognitive and behavioral impairments, the long term consequences of children with TBI required further studies. 


\section{Acknowledgements:}

The authors are grateful to the victims for their cooperation in data collection. The authors would like to thank all those who assisted in carrying out this study: Nadia Baguena, Jean Yves Bar, Amélie Boulanger, Stuart Nash, Véronique Sotton, for collecting the data, Irène Vergnes for organizing the databases; Anne-Marie Bigot, Nathalie Demangel, Geneviève Boissier for subject database management; Blandine Gadegbeku, Amina Ndiaye and The Association for the Rhône Road Trauma Registry (ARVAC) for their help in collecting and providing medical data; the Scientific Committee (Daniel Floret, François Chapuis, Jean Michel Mazaux, Jean Louis Martin, Jacques Gaucher); all the hospital staff who accepted the interviewers' presence and referred victims; and the SAMU team who reported their daily emergency interventions. Special thanks to Jean-Louis Martin and Vivian Viallon for statistical analysis advice.

We acknowledge funding from the French Ministry of Equipment, Transport, Housing, Tourism and Sea (Program Predit 3 "New Knowledge in the Field of Road Safety": N SU0400066) and from the French Ministry of Health (Program PHRC 2003: PHRC-N03 and PHRC 2005: PHRCN051).

The individual authors have no competing interests to declare. 


\section{References:}

Aitken, M.E., Mccarthy, M.L., Slomine, B.S., Ding, R., Durbin, D.R., Jaffe, K.M., Paidas, C.N., Dorsch, A.M., Christensen, J.R., Mackenzie, E.J., Group, C.S., 2009. Family burden after traumatic brain injury in children. Pediatrics 123 (1), 199-206.

Aitken, M.E., Tilford, J.M., Barrett, K.W., Parker, J.G., Simpson, P., Landgraf, J., Robbins, J.M., 2002. Health status of children after admission for injury. Pediatrics 110 (2 Pt 1), 337-42.

Anderson, V., Catroppa, C., Morse, S., Haritou, F., Rosenfeld, J., 2005a. Functional plasticity or vulnerability after early brain injury? Pediatrics 116 (6), 1374-82.

Anderson, V.A., Catroppa, C., Haritou, F., Morse, S., Rosenfeld, J.V., 2005b. Identifying factors contributing to child and family outcome 30 months after traumatic brain injury in children. $J$ Neurol Neurosurg Psychiatry 76 (3), 401-8.

Barnes, J., Thomas, P., 2006. Quality of life outcomes in a hospitalized sample of road users involved in crashes. Annu Proc Assoc Adv Automot Med 50, 253-68.

Chandran, A., Hyder, A.A., Peek-Asa, C., 2010. The global burden of unintentional injuries and an agenda for progress. Epidemiol Rev 32 (1), 110-20.

Charnay, P., Laumon, B., 2002. Le registre des victimes d'accidents de la circulation du rhône: Modalités de mise en place, de recueil, d'informatisation et de gestion. INRETS, Lyon, France.

Ding, R., Mccarthy, M.L., Houseknecht, E., Ziegfeld, S., Knight, V.M., Korehbandi, P., Parnell, D., Klotz, P., Group, C.S., 2006. The health-related quality of life of children with an extremity fracture: A one-year follow-up study. J Pediatr Orthop 26 (2), 157-63.

Eiser, C., Morse, R., 2001. Can parents rate their child's health-related quality of life? Results of a systematic review. Qual Life Res 10 (4), 347-57.

Gofin, R., Adler, B., Hass, T., 1999. Incidence and impact of childhood and adolescent injuries: A population-based study. J Trauma 47 (1), 15-21.

Haukeland, J.V., 1996. Welfare consequences of injuries due to traffic accidents. Accident Analysis and Prevention 28 (1), 63-72.

Healthactchq, 2008. The chq scoring and interpretation manual. HealthActCHQ, Cambridge, MA.

Hours, M., Bernard, M., Charnay, P., Chossegros, L., Javouhey, E., Fort, E., Boisson, D., Sancho, P.O., Laumon, B., 2010. Functional outcome after road-crash injury: Description of the esparr victims cohort and 6-month follow-up results. Accid Anal Prev 42 (2), 412-21.

Javouhey, E., Gadegbeku, B., Ndiaye, A., Laumon, B., 2012. Traumatologie routière infantile et dispositifs de protection : Données issues du registre du rhône. Urgences 2012. Masson ed.

Landgraf, J.M., Maunsell, E., Speechley, K.N., Bullinger, M., Campbell, S., Abetz, L., Ware, J.E., 1998. Canadian-french, german and uk versions of the child health questionnaire: Methodology and preliminary item scaling results. Qual Life Res 7 (5), 433-45.

Mackenzie, E.J., Siegel, J.H., Shapiro, S., Moody, M., Smith, R.T., 1988. Functional recovery and medical costs of trauma: An analysis by type and severity of injury. J Trauma 28 (3), 281-97.

Max, J.E., Koele, S.L., Lindgren, S.D., Robin, D.A., Smith, W.L., Jr., Sato, Y., Arndt, S., 1998. Adaptive functioning following traumatic brain injury and orthopedic injury: A controlled study. Arch Phys Med Rehabil 79 (8), 893-9.

Mccarthy, M.L., Mackenzie, E.J., Durbin, D.R., Aitken, M.E., Jaffe, K.M., Paidas, C.N., Slomine, B.S., Dorsch, A.M., Christensen, J.R., Ding, R., Children's Health after Trauma Study, G., 2006. Health-related quality of life during the first year after traumatic brain injury. Arch Pediatr Adolesc Med 160 (3), 252-60.

Nhac-Vu, H.T., Hours, M., Charnay, P., Chossegros, L., Boisson, D., Luaute, J., Javouhey, E., Ndiaye, A., Laumon, B., 2011. Predicting self-reported recovery one year after major road traffic accident trauma. J Rehabil Med 43 (9), 776-82.

Peden, M., Oyegbite, K., Ozanne-Smith, J., Hyder, A.A., Branche, C., Rahman, A.F., Rivara, F., Bartolomeos, K., 2008. World report on child injury prevention chapter 1: Child injuries in context. World Health Organization, UNICEF, Geneva, Switzerland. 
Polinder, S., Meerding, W.J., Toet, H., Mulder, S., Essink-Bot, M.L., Van Beeck, E.F., 2005. Prevalence and prognostic factors of disability after childhood injury. Pediatrics 116 (6), e810-7.

Soberg, H.L., Bautz-Holter, E., Roise, O., Finset, A., 2007. Long-term multidimensional functional consequences of severe multiple injuries two years after trauma: A prospective longitudinal cohort study. J Trauma 62 (2), 461-70.

Stancin, T., Drotar, D., Taylor, H.G., Yeates, K.O., Wade, S.L., Minich, N.M., 2002. Health-related quality of life of children and adolescents after traumatic brain injury. Pediatrics 109 (2), E34.

Sturms, L.M., Van Der Sluis, C.K., Groothoff, J.W., Ten Duis, H.J., Eisma, W.H., 2003. Young traffic victims' long-term health-related quality of life: Child self-reports and parental reports. Arch Phys Med Rehabil 84 (3), 431-6.

Taylor, H.G., Yeates, K.O., Wade, S.L., Drotar, D., Klein, S.K., Stancin, T., 1999. Influences on first-year recovery from traumatic brain injury in children. Neuropsychology 13 (1), 76-89.

Waters, E.B., Salmon, L.A., Wake, M., Wright, M., Hesketh, K.D., 2001. The health and well-being of adolescents: A school-based population study of the self-report child health questionnaire. J Adolesc Health 29 (2), 140-9.

Wesson, D.E., Scorpio, R.J., Spence, L.J., Kenney, B.D., Chipman, M.L., Netley, C.T., Hu, X., 1992. The physical, psychological, and socioeconomic costs of pediatric trauma. J Trauma 33 (2), 252-5; discussion 255-7. 
Tables:

Table 1. Comparison of the respondents to one year questionnaire of the pediatric ESPARR cohort with children of the Rhône registry stratified by M-AIS score.

\begin{tabular}{|c|c|c|c|c|c|c|}
\hline \multirow[b]{2}{*}{ Characteristics } & \multicolumn{3}{|c|}{ M-AIS $<3$} & \multicolumn{3}{|c|}{ M-AIS $\geq 3$} \\
\hline & $\begin{array}{l}\text { Registry }^{\mathrm{a}} \\
\mathrm{n}=1170\end{array}$ & $\begin{array}{l}\text { ESPARR } \\
n=104\end{array}$ & p-value & $\begin{array}{l}\text { Registry }^{\mathrm{a}} \\
\mathrm{n}=113\end{array}$ & $\begin{array}{l}\text { ESPARR } \\
n=23\end{array}$ & p-value \\
\hline Age at crash, n $(\%)$ & & & 0.55 & & & 0.84 \\
\hline $0-5$ years & $216(18.5)$ & $21(20.2)$ & & $10(8.8)$ & $3(13.0)$ & \\
\hline $6-11$ years & $439(37.5)$ & $43(41.3)$ & & $44(38.9)$ & $9(39.1)$ & \\
\hline $12-16$ years & $515(44.0)$ & $40(38.5)$ & & $59(52.2)$ & $11(47.8)$ & \\
\hline Male gender, $\mathrm{n}(\%)$ & $802(68.5)$ & $66(63.5)$ & 0.34 & $81(71.7)$ & $16(69.6)$ & 0.96 \\
\hline Type of road user, n (\%) & & & 0.01 & & & 0.04 \\
\hline Pedestrian & $209(19.0)$ & $22(21.2)$ & & $20(17.7)$ & $6(26.1)$ & \\
\hline Four-wheeled occupants & $241(21.9)$ & $34(32.7)$ & & $11(9.7)$ & $3(13.0)$ & \\
\hline Motorized two-wheeled drivers & $153(13.9)$ & $18(17.3)$ & & $17(15.0)$ & $8(34.8)$ & \\
\hline Other (cyclist. rollerblade/scooter user) & $496(45.1)$ & $30(28.9)$ & & $59(52.2)$ & $6(26.0)$ & \\
\hline Unknown & 71 & 0 & & 6 & 0 & \\
\hline
\end{tabular}

M-AIS: Maximum Abbreviated Injury Scale; ESPARR: Etude de Suivi d'une Population d'Accidentés de la Route dans le Rhône.

${ }^{a}$ Excluding ESPARR 
Table 2. Characteristics at inclusion of the pediatric ESPARR cohort according to health status recovery 1 year after a road accident.

\begin{tabular}{clll}
\hline & \multicolumn{3}{c}{ health status } \\
\cline { 2 - 4 } Inclusion characteristics & $\begin{array}{l}\text { fully recovered } \\
\mathrm{n}(\%)\end{array}$ & $\begin{array}{l}\text { Not fully recovered } \\
\mathrm{n}(\%)\end{array}$ & $\begin{array}{l}\text { Crude Weighted } \\
\text { Odds Ratio (95\% CI) }\end{array}$ \\
\hline Gender ( $\mathrm{n}=127)$ & $57(66.3)$ & $25(61.0)$ & 1 \\
Male & $29(33.7)$ & $16(39.0)$ & $1.30(0.59-2.91)$
\end{tabular}

Age at the time of the crash (year) $(n=127)$

$\begin{array}{llll}0-5 & 22(25.6) & 2(4.9) & 0.18(0.04-0.88) \\ 6-11 & 34(39.5) & 18(43.9) & 0.90(0.39-2.07) \\ 12-16 & 30(34.9) & 21(51.2) & 1^{\mathrm{a}}\end{array}$

Familial socio-professional level $(\mathrm{n}=114)$

Low

$\begin{array}{lll}31(40.7) & 16(45.7) & 1 \\ 27(35.1) & 12(34.3) & 0.83(0.33-2.09) \\ 19(24.7) & 7(20.0) & 0.69(0.23-2.07)\end{array}$

Urban renewal area $(n=127)$

No

Yes

Family condition $(\mathrm{n}=127)$

lives with 1 to 4 persons

lives with at least 5 persons

Type of road users $(n=127)$

Four-wheeled occupants

Motorized two-wheeled drivers

Pedestrian

Other (cyclist. scooter and roller users)

\section{$76(88.4)$}

10 (11.6)
$75(87.2)$

$11(12.8)$

\section{8 (32.6)}

$14(16.3)$

$16(18.6)$

28 (32.6)

M-AIS ( $\mathrm{n}=127)$

$$
\begin{aligned}
& <3 \\
& \geq 3
\end{aligned}
$$

Injury (AIS>1) $(\mathrm{n}=127)^{\mathrm{c}}$

$$
\begin{aligned}
& 78(90.7) \\
& 8(9.3)
\end{aligned}
$$

$\begin{array}{llll}\text { Head } & 17(19.8) & 14(34.2) & 2.45(1.02-5.88)^{\mathrm{b}} \\ \text { Face } & 2(2.3) & 3(7.3) & 3.41(0.48-24.11) \\ \text { Spine } & 1(1.2) & 2(4.9) & 3.78(0.31-45.98) \\ \text { Chest } & 1(1.2) & 3(7.3) & 3.68(0.36-37.32) \\ \text { Abdomen } & 3(3.5) & 3(7.3) & 1.85(0.33-10.29) \\ \text { Lower limbs } & 7(8.1) & 16(39.0) & 6.15(2.16-17.47)^{\mathrm{b}} \\ \text { Upper limbs } & 5(5.8) & 4(9.8) & 1.06(0.26-4.32)\end{array}$

35 (85.4)

6 (14.6)

$1.26(0.40-3.95)$

$32(78.1)$

$1^{\mathrm{a}}$

$9(22.0)$

$2.02(0.73-5.62)$

ESPARR: Etude de Suivi d'une Population d'Accidentés de la Route dans le Rhône; M-AIS: Maximum Abbreviated Injury Scale ; CI: Confidence Interval.

${ }^{\mathrm{a}} 0.05<\mathrm{p}<0.20$

${ }^{\mathrm{b}} \mathrm{p}<0.05$

${ }^{\mathrm{c}}$ The reference was the remainder of the pediatric ESPARR cohort 
Table 3. Factors associated with full health status recovery 1 year after a road accident (multivariate analysis) (pediatric ESPARR cohort) $(n=127)$

\begin{tabular}{llc}
\hline Characteristics & $\begin{array}{l}\text { Adjusted Weighted } \\
\text { Odds Ratio }(95 \% \mathrm{CI})^{\mathrm{a}}\end{array}$ & p-value \\
\hline Lower limb injury (AIS $>1)$ & $6.45(1.92-21.68)$ & 0.003 \\
M-AIS $\geq 3$ vs M-AIS $<3$ & $4.34(1.29-14.59)$ & 0.02 \\
Age at the time of the crash (year) & & 0.21 \\
$0-5$ & $0.19(0.03-1.35)$ & \\
$6-11$ & $1.14(0.44-2.98)$ & \\
$12-16$ & 1
\end{tabular}

Gender

0.19

Male vs. Female

$1.96(0.72-5.37)$

ESPARR: Etude de Suivi d'une Population d'Accidentés de la Route dans le Rhône; M-AIS: Maximum Abbreviated Injury Scale; CI: Confidence Interval.

${ }^{a}$ Adjusted of familial socio-professional level 
Table 4. Correlation of the CHQ-PF50 quality of life questionnaire with the health status recovery 1 year after a road accident (pediatric ESPARR cohort).

\begin{tabular}{lcc} 
Quality of life (CHQ-PF50) & correlation coefficient & p-value \\
\hline Physical Functioning $(\mathrm{n}=93)$ & 0.347 & 0.001 \\
Role/Social - Physical $(\mathrm{n}=94)$ & 0.502 & $<0.001$ \\
General Heath $(\mathrm{n}=93)$ & 0.246 & 0.02 \\
Body Pain $(\mathrm{n}=94)$ & 0.482 & $<0.001$ \\
\hline Physical score $(\mathrm{n}=86)$ & 0.456 & $<0.001$ \\
\hline Mental Health $(\mathrm{n}=94)$ & 0.159 & 0.13 \\
Role/Social limitation-Emotional $(\mathrm{n}=92)$ & 0.310 & 0.003 \\
Parental Impact-Time (n=93) & 0.288 & 0.005 \\
Parental Impact-Emotional (n=93) & 0.335 & 0.001 \\
Self-Esteem (n=91) & 0.179 & 0.09 \\
Behaviour (n=94) & 0.196 & 0.06 \\
\hline Psychosocial score $(\mathrm{n}=86)$ & 0.213 & 0.05 \\
\hline Family Activities $(\mathrm{n}=94)$ & 0.152 & 0.14 \\
Family cohesion $(\mathrm{n}=94)$ & 0.051 & 0.62
\end{tabular}

CHQ-PF50: Child Health Questionnaire-Parent Form 50; ESPARR: Etude de Suivi d'une Population d'Accidentés de la Route dans le Rhône. 